\title{
Antioxidant effects of methylprednisolone and hydrocortisone on the impairment of endothelium dependent relaxation induced by reactive oxygen species in rabbit abdominal aorta
}

Hee Jong Lee, Jung Kook Suh, Hyun Hoo Song, Mi Ae Jeong, Jong Hoon Yeom, and Dong Won Kim

Department of Anesthesiology and Pain Medicine, Hanyang University Hospital, Seoul, Korea

Background: The reperfusion following ischemia produces reactive oxygen species (ROS). We studied the influences of methylprednisolone (MPD) and hydrocortisone (CRT) on ROS effects using the endothelium of rabbit abdominal aorta.

Methods: Isolated rabbit aortic rings were suspended in an organ bath filled with Krebs-Henseleit (K-H) solution. After precontraction with norepinephrine, changes in arterial tension were recorded following the cumulative administration of acetylcholine (ACh). The percentages of ACh-induced relaxation of aortic rings before and after exposure to ROS, generated by electrolysis of K-H solution, were used as the control and experimental values, respectively. The aortic rings were pretreated with MPD or CRT at the same concentrations, and the effects of these agents were compared with the effects of ROS scavenger inhibitors: superoxide dismutase inhibitor, diethylthiocarbamate (DETCA), and the catalase inhibitor, 3-amino-1,2,4-triazole (3AT).

Results: Both MPD and CRT maintained endothelium-dependent relaxation induced by ACh in a dose-related manner in spite of ROS attack. The restored ACh-induced relaxation of MPD and CRT group was not attenuated by pretreatment of 3AT and DETCA.

Conclusions: MPD and CRT preserve the endothelium-dependent vasorelaxation against the attack of ROS, in a dose-related manner. Endothelial protection mechanisms of MPD and CRT may be not associated with hydrogen peroxide and superoxide scavenging. (Korean J Anesthesiol 2013; 64: 54-60)

Key Words: Diethylthiocarbamate, Endothelium, Hydrocortisone, Methylprednisolone, Reactive oxygen species, 3-amino-1,2,4-triazole.

Received: July 13, 2012. Revised: 1st, September 16, 2012; 2nd, October 5, 2012; 3rd, October 12, 2012. Accepted: October 13, 2012. Corresponding author: Jung Kook Suh, M.D., Ph.D., Department of Anesthesiology and Pain Medicine, Hanyang University Hospital, 17, Haengdang-dong, Sungdong-gu, Seoul 133-777, Korea. Tel: 82-2-2290-8680, Fax: 82-2-2299-8692, E-mail: jksuh@hanyang.ac.kr

(c) This is an open-access article distributed under the terms of the Creative Commons Attribution Non-Commercial License (http:// creativecommons.org/licenses/by-nc/3.0/), which permits unrestricted non-commercial use, distribution, and reproduction in any medium, provided the original work is properly cited. 


\section{Introduction}

After Furchgott and Zawadzki [1] revealed in 1980 that an endothelium-derived relaxing factor (EDRF) is released from vascular endothelium, Palmer et al. [2] proved in 1987 that the EDRF was nitric oxide (NO). Whereas the conventional view attributed tissue injury process to ischemia itself, Bulkley [3] found that a variable proportion of the injury is caused by toxic oxygen metabolites that are generated from xanthine oxidase at the time of reperfusion. The metabolites were named reactive oxygen species (ROS) and included: superoxide radical $\left(\mathrm{O}_{2} \cdot{ }^{\cdot}\right)$, hydrogen peroxide $\left(\mathrm{H}_{2} \mathrm{O}_{2}\right)$, and hydroxyl radical $(\mathrm{OH} \cdot)$ [3]. Endothelium is particularly liable to damage by ROS [4], and endothelial dysfunction occurs after ischemia and reperfusion, characterized by a marked reduction in endothelium-dependent relaxation due to reduced release or action of EDRF [5]. Clinically, reperfusion injury may be possible by ischemic condition, including surgery, such as coronary artery bypass graft surgery, repair of aneurysm, and transplantation [6]. Fortunately, some intravenous and volatile anesthetics have antioxidant and free radical scavenging properties [7], and local anesthetics also attenuates cell injury induced by ischemicreperfusion [8].

Steroid is known to have neuroprotection effects in acute spinal-cord injury [9]. However, no study has yet shown that steroid has endothelial protection effect in the ischemiareperfusion injury by ROS. In addition, dexamethasone to treat brain edema relate to the expression of vascular endothelial growth factor rather than the protection of brain-derived microvessel endothelial cells [10].

We studied the influence of methylprednisolone (MPD) and hydrocortisone (CRT) on ROS effects using the endothelium of rabbit abdominal aorta to examine if their anti-oxidizing effects can suppress or reduce the vascular endothelium injury by ROS.

\section{Materials and Methods}

\section{Preparation of ring slices and recording}

All experiments were conducted conforming to the regulations of the Laboratory Animal Committee. Auricular intravenous injection of heparin $600 \mathrm{IU} / \mathrm{kg}$ was carried out in the rabbits under sevoflurane inhalation anesthesia, and exsanguinations followed after 3 minutes by cleaving the carotid artery. The abdominal aortas of the rabbits $(2-2.5 \mathrm{~kg}$, Male, $\mathrm{n}=27$ ) were extirpated and $3-4 \mathrm{~mm}$ long ring slices were prepared by separating the lipid tissue and connective tissue, without engaging tension on them, in a petri dish containing Krebs- Henseleit solution (K-H solution: $\mathrm{NaCl} 120.0$, NaHCO3 25.0, $\mathrm{KCl}$ 5.0, $\mathrm{MgSO} 4$ 1.2, $\mathrm{CaCl} 2$ 2.5, $\mathrm{NaH} 2 \mathrm{PO} 4$ 1.4, glucose 11.0
$\mathrm{mM}$ ), and $95 \%$ oxygen and $5 \%$ carbon dioxide were insufflated. While maintaining the temperature at $37 \pm 0.5^{\circ} \mathrm{C}$, one end of the aorta slice was fixed in the tissue bath containing $5 \mathrm{ml}$ of K-H solution. The opposite end was connected to a force displacement transducer (TSD $125^{\circledR}$, Biopac Inc., USA), and the K-H solution was exchanged every 15 minutes during the 90-minute equilibration period. The resting stage tension was fixed at $2.0 \mathrm{~g}$. The vascular smooth muscle tension was recorded using an amplifier (DA100C ${ }^{\circledR}$, Biopac Inc., USA) with a data acquisition system (MP100 ${ }^{\circledR}$, Biopac Inc., USA) and a personal computer. Following the precontraction with norepinephrine (NE) $10^{-6} \mathrm{M}$, acetylcholine (ACh) $3 \times 10^{-8}, 10^{-7}, 3 \times 10^{-7}$, and $10^{-6}$ $\mathrm{M}$ were consecutively injected to observe the change of the aortic tone. Changes of the aortic tone by ACh injection before ROS exposure (control) and after ROS exposure (experimental) were compared.

\section{Method of exposure to ROS}

After obtaining the control group values by the consecutive injection of $\mathrm{ACh}$, each reagent was pretreated, and following a necessary interval, electrolysis was carried out by applying an electric current (constant current, $15 \mathrm{~mA}$ ) to the positive and negative electrodes in the $\mathrm{K}-\mathrm{H}$ solution for 35 seconds to generate ROS and induce vascular endothelial injury. In the procedure, distance over $1 \mathrm{~cm}$ was maintained between the abdominal aorta ring slices and the positive and negative electrodes to avoid a direct stimulus of the electric field to the tissue. The K-H solution was exchanged, the precontrcaction by NE followed, and Ach was consecutively injected. Changes in the aortic tone were recorded as the experimental group values. The electrode was made of platinum $(7.5 \mathrm{~mm})$, and $15 \mathrm{~mA}$ of constant current generation was tested before the experiment.

\section{Precontraction with NE and relaxation with $\mathrm{ACh}$ : control value}

At the beginning of every experiment, precontraction was induced with NE $\left(10^{-6} \mathrm{M}\right)$, and once a stable tension plateau was established, Ach $\left(3 \times 10^{-8}, 10^{-7}, 3 \times 10^{-7}\right.$, and $\left.10^{-6} \mathrm{M}\right)$ were consecutively administered to observe the change of isometric tension (control value). We only used viable ring segments that showed more than $80 \%$ relaxation of aortic tension for the following procedures. We sustained $15 \mathrm{~min}$ of equilibrating period.

\section{Effect of MPD and CRT pretreatment}

After obtaining the control group values of the response to ACh before ROS exposure, the experimental group values were 
obtained by 15 minutes of experimental drug pretreatment, followed by exposure to the ROS for 35 seconds. Then, the K-H solution was exchanged, the precontrcaction by NE followed, and ACh was consecutively injected. The experimental groups included one group pretreated with MPD $\left(10^{-4} \mathrm{M}: \mathrm{n}=10,3 \times 10^{-4}\right.$ M: $\mathrm{n}=14,10^{-3} \mathrm{M}: \mathrm{n}=11,3 \times 10^{-3} \mathrm{M}: \mathrm{n}=14$ ) and the other group pretreated with CRT $\left(10^{-4} \mathrm{M}: \mathrm{n}=11,3 \times 10^{-4} \mathrm{M}: \mathrm{n}=14,10^{-3} \mathrm{M}: \mathrm{n}\right.$ $=6,3 \times 10^{-3} \mathrm{M}: \mathrm{n}=12$ ), using concentrations of $10^{-4}, 3 \times 10^{-4}, 10^{-3}$ and $3 \times 10^{-3} \mathrm{M}$.

\section{Effect of 3-amino-1,2,4-triazole (3AT) on vascular endothelial injury by ROS}

The samples were pretreated with $5 \mathrm{mM} 3 \mathrm{AT}$, the catalase inhibitor, for 30 minutes [11]. After 3AT treatment for 15 minutes, $3 \times 10^{-3} \mathrm{M}$ of MPD $(\mathrm{n}=7)$ and CRT $(\mathrm{n}=11)$ were additionally added, and treatment was conducted for 15 minutes. Following 35 seconds of electrolysis to generate ROS, the $\mathrm{K}-\mathrm{H}$ solution was exchanged, the precontrcaction by $\mathrm{NE}$ followed, and ACh was consecutively injected.

\section{Effect of diethylthiocarbamate (DETCA) on vascular endothelial injury by ROS}

The samples were pretreated with 0.5 mM DETCA, superoxide dismutase inhibitor, for 30 minutes. After DETCA treatment for 15 minutes, $3 \times 10^{-3} \mathrm{M}$ of MPD $(\mathrm{n}=7)$ and CRT $(\mathrm{n}=11)$ were additionally added, and treatment was conducted for 15 minutes. Following 35 seconds of electrolysis to generate ROS, the K-H solution was exchanged, the precontrcaction by $\mathrm{NE}$ followed, and Ach was consecutively injected.

\section{Reagents}

The reagents NE, ACh, 3AT, DETCA, were purchased from Sigma Co. (St. Louis, USA). The MPD was Solumedrol ${ }^{\circledR}$ (Pfizer Pharmacy, Korea), and the CRT was Solu-cortef ${ }^{\circledR}$ (Pfizer Pharmacy, Korea).

\section{Statistical procedure}

The degree of aortic tone relaxation by Ach was expressed as the percentage relaxation of the precontraction induced by NE $\left(10^{-6} \mathrm{M}\right)$. Data was presented as mean \pm SE. Statistical analysis was performed using Prism 2.0 ${ }^{\mathrm{TM}}$ (GraphPad software, San Diego, USA). N indicates the number of rabbit abdominal aortic rings. For the comparison of the results among the pretreated MPD and CRT concentrations, a one-way ANOVA was used. A paired t-test was used for the comparison of results before and after the ROS exposure, while an unpaired t-test was used for the comparison of the results between the 3AT or DETCA pretreated group and the non-pretreated group. All the posthoc tests were carried out by the Dunnet test, defining statistical significance as $\mathrm{P}<0.05$.

\section{Results}

\section{Vascular relaxation before ROS exposure (control)}

Aorta ring segment contraction was induced by NE $10^{-6} \mathrm{M}$ into a stable tension plateau. Cumulative ACh $\left(3 \times 10^{-8}, 10^{-7}, 3 \times\right.$ $10^{-7}$, and $10^{-6} \mathrm{M}$ ) administration following the plateau gave rise to aorta ring segment relaxation in a dose-dependent manner. The percentage of aortic tone relaxation by Ach was $-93.3 \pm 0.8 \%$.

\section{Vascular relaxation after vascular endothelial injury induction with ROS}

MPD $10^{-4}, 3 \times 10^{-4}, 10^{-3}$, and $3 \times 10^{-3} \mathrm{M}$ groups enhanced relaxation by ACh $10^{-6} \mathrm{M}$ in a dose-dependent manner. The percentage of aortic tone change by $\mathrm{ACh} 10^{-6} \mathrm{M}$ was $-4.6 \pm 2.9$, $-17.6 \pm 3.1,-66.0 \pm 4.6$, and $-75.7 \pm 3.6 \%$ in each, respectively. Comparing the MPD $10^{-4} \mathrm{M}$ group with the MPD $3 \times 10^{-4}, 10^{-3}$, and $3 \times 10^{-3} \mathrm{M}$ groups, the percentage change of aortic tone was affected by MPD concentration with statistical significance (Fig. 1).

CRT $10^{-4}, 3 \times 10^{-4}, 10^{-3}$, and $3 \times 10^{-3} \mathrm{M}$ groups enhanced relaxation by ACh $10^{-6} \mathrm{M}$ in a dose-dependent manner. The percentage of aortic tone change by ACh $10^{-6} \mathrm{M}$ was $-2.0 \pm 3.2$, $-16.0 \pm 3.9,-52.0 \pm 5.5$, and $-78.8 \pm 2.2 \%$ in each, respectively. Comparing the CRT $10^{-4} \mathrm{M}$ group with the CRT $3 \times 10^{-4}, 10^{-3}$,

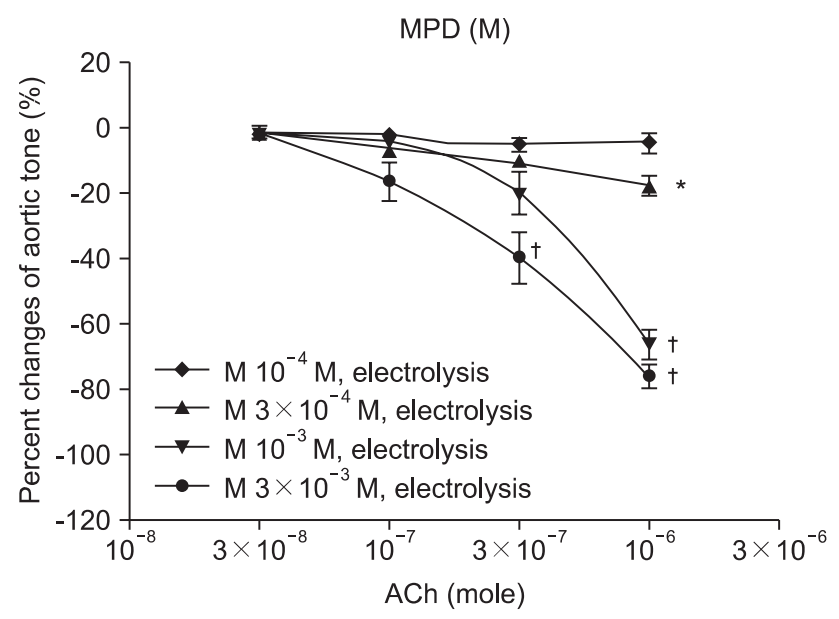

Fig. 1. Effects of varied-dose methylprednisolone pretreatment $\left(10^{-4}, 3 \times 10^{-4}, 10^{-3}\right.$ and $\left.3 \times 10^{-3} \mathrm{M}\right)$ on the reactive oxygen species attack. Data are presented as mean \pm SE. ACh: acetylcholine, MPD: methylprednisolone. ${ }^{*} \mathrm{P}<0.05,{ }^{\dagger} \mathrm{P}<0.01$, compared with MPD $10^{-4}$ M group. 
and $3 \times 10^{-3} \mathrm{M}$ groups, the percentage change of aortic tone was affected by CRT concentration with statistical significance (Fig. 2).

\section{Effect of 3AT on vascular endothelial injury by ROS}

In the case of the MPD pretreated group $\left(3 \times 10^{-3} \mathrm{M}\right)$, no significant change was found in the 3 AT pretreated group $(-77.2$ $\pm 2.4 \%)$ compared with the unpretreated group $(-86.0 \pm 5.2 \%)$ (Fig. 3). As well in the case of the CRT pretreated group $(3 \times$ $\left.10^{-3} \mathrm{M}\right)$, no significant change was found in the 3AT pretreated group $(-88.8 \pm 0.8 \%)$ compared with the unpretreated group $(-88.6 \pm 1.9 \%)$ (Fig. 4).

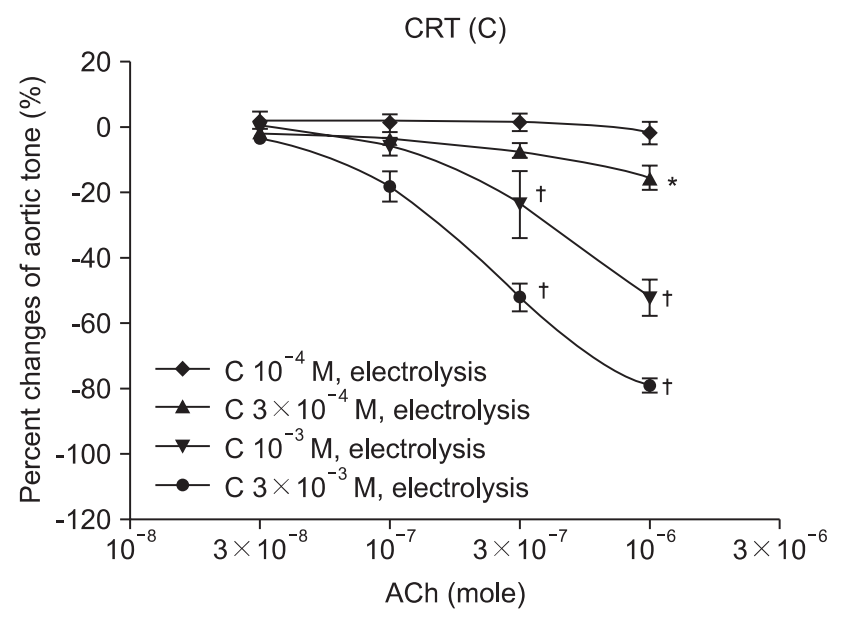

Fig. 2. Effects of varied-dose hydrocortisone pretreatment $\left(10^{-4}\right.$, $3 \times 10^{-4}, 10^{-3}$ and $3 \times 10^{-3} \mathrm{M}$ ) on the reactive oxygen species attack. Data are presented as mean \pm SE. ACh: acetylcholine, CRT: hydrocortisone. ${ }^{*} \mathrm{P}<0.05,{ }^{\dagger} \mathrm{P}<0.01$, compared with CRT $10^{-4} \mathrm{M}$ group.

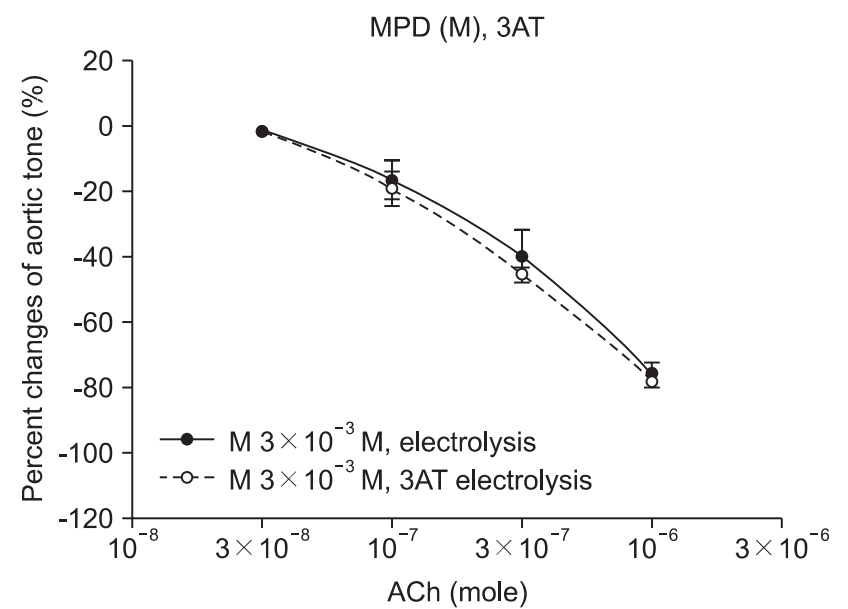

\section{Effect of DETCA on vascular endothelial injury by ROS}

In the case of the MPD pretreated group $\left(3 \times 10^{-3} \mathrm{M}\right)$, no significant change was found in the DETCA pretreated group $(-78.7 \pm 3.9 \%)$ compared with the unpretreated group $(-89.2$ $\pm 0.6 \%$ ) (Fig. 3). As well in the case of the CRT pretreated group $\left(3 \times 10^{-3} \mathrm{M}\right)$, no significant change was found in the DETCA pretreated group $(-77.9 \pm 2.2 \%)$ compared with the unpretreated group $(-89.7 \pm 1.7 \%)$ (Fig. 4$)$.

\section{Discussion}

Reactive oxygen species (ROS) are normally generated at basal amounts, but ischemia or oxygen re-supply during reperfusion lead to abnormally high ROS levels which cannot be cleared by normal anti-oxidizing systems, causing tissue reperfusion injury [12]. In this process, an oxygen $\left(\mathrm{O}_{2}\right)$ molecule generates the intermediate species, $\mathrm{O}_{2} \cdot \mathrm{H}_{2} \mathrm{O}_{2}$, and $\mathrm{OH} \cdot$ and the intermediates $\mathrm{O}_{2} \cdot$ and $\mathrm{OH} \cdot$ are important free radicals that cause peroxidation (LOO·) of intracellular lipids and tissue damage [13]. In particular, $\mathrm{OH} \cdot$, the most reactive ROS [1] is produced by the Fenton reaction $\left(\mathrm{Fe}^{2+}+\mathrm{HOOH} \rightarrow \mathrm{Fe}^{3+}+\mathrm{OH}^{\cdot}+\mathrm{OH}^{-}\right)$and the Haber-Weiss reaction $\mathrm{O}_{2} \cdot{ }^{-}+\mathrm{NO} \rightarrow \mathrm{OONO}^{-}+\mathrm{H}^{+} \rightarrow \mathrm{OONOH}$ $\rightarrow \mathrm{NOO}^{*}+\mathrm{OH}^{\cdot}$ ) [13]. ROS generated during reperfusion causes organ damage in the heart $[14,15]$, brain $[16,17]$, and blood vessels $[18,19]$.

In 1980, Furchgott and Zawadzki [1] found an EDRF later shown to be NO [2]. Other vasoactive substances, including endothelium-derived hyperpolarizing factor and the endothelium-derived contracting factor, are released from the endothelium to regulate vascular tone. However, because the endothelium is composed of a cell monolayer, it is easily

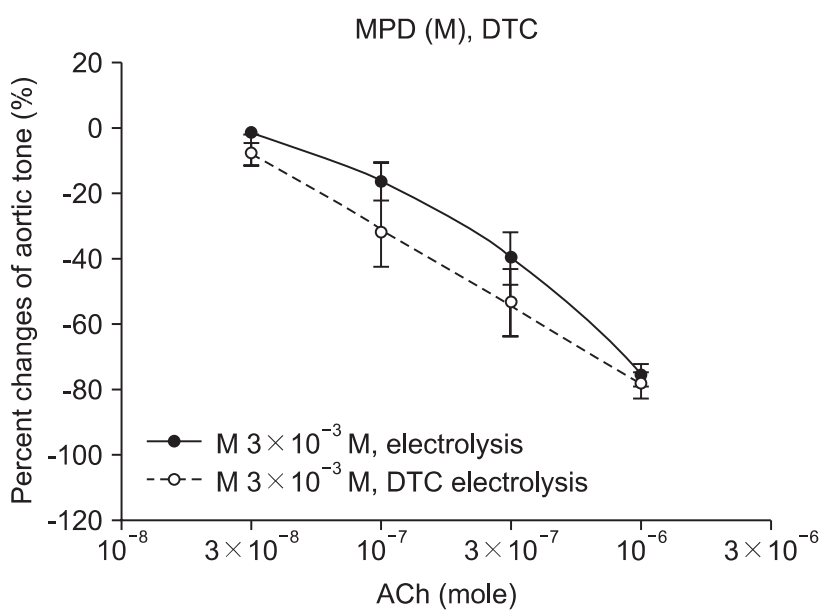

Fig. 3. The antioxidant effect of methylprednisolone $3 \times 10^{-3} \mathrm{M}$ group is not attenuated by pretreatment of $3 \mathrm{AT}$ (MPD $3 \times 10^{-3} \mathrm{M}$ with $3 \mathrm{AT}$ ) and DETCA (MPD $3 \times 10^{-3} \mathrm{M}$ with DTC). Data are presented as mean \pm SE. ACh: acetylcholine, MPD: methylprednisolone, 3AT: 3-Amino-1,2,3Triazole, DTC = DETCA: diethylthiocarbamate. 

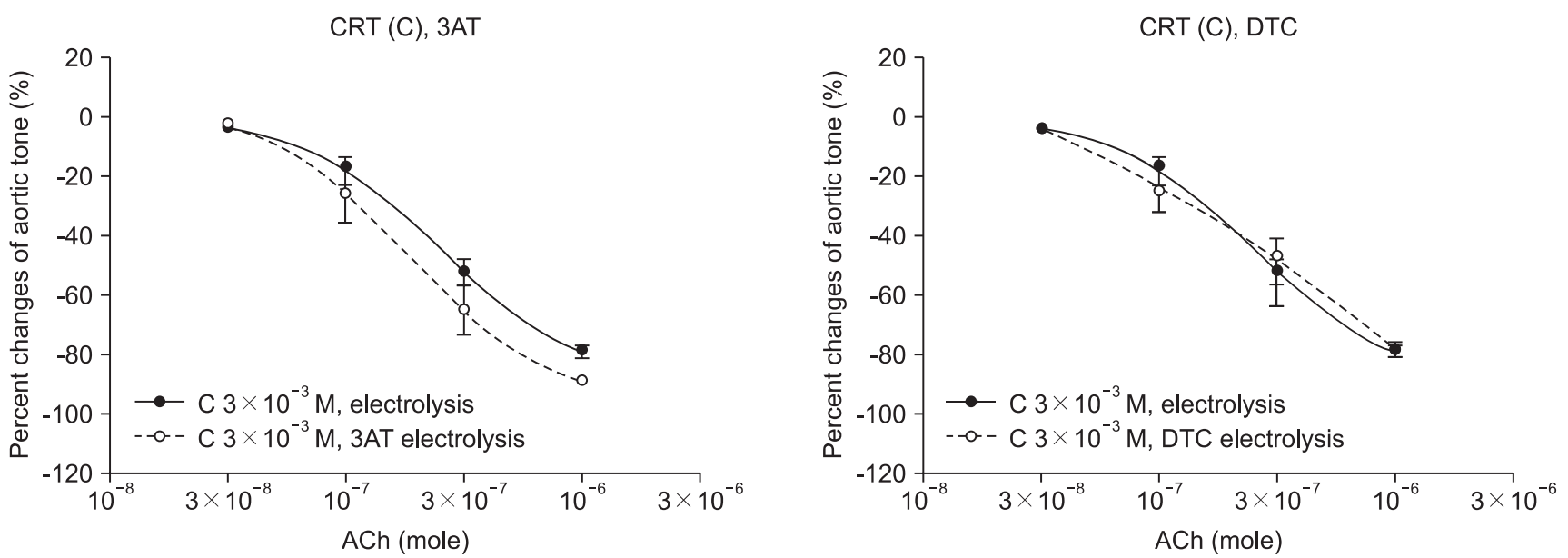

Fig. 4. The antioxidant effect of hydrocortisone $3 \times 10^{-3} \mathrm{M}$ group is not attenuated by pretreatment of $3 \mathrm{AT}$ (CRT $3 \times 10^{-3} \mathrm{M}$ with $3 \mathrm{AT}$ ) and DETCA (CRT $3 \times 10^{-3} \mathrm{M}$ with DTC). Data are presented as mean \pm SE. ACh: acetylcholine, CRT: hydrocortisone, 3AT: 3-Amino-1,2,3-Triazole, DTC $=$ DETCA: diethylthiocarbamate.

damaged by physical and chemical stimuli, including ROS during reperfusion. Inhalation anesthetics $[12,15,20]$ and lidocaine, a local anesthetics, can prevent ischemia-reperfusion injury in the brain [13]. Steroid is known to have neouroprotection effects in acute spinal-cord injury [9]. However, no study has shown that steroid has endothelial protection effect in the ischemia-reperfusion injury by ROS. In addition, dexamethasone to treat brain edema relate to the expression of vascular endothelial growth factor rather than the protection of brain-derived microvessel endothelial cells [10].

We studied the influence of MPD and CRT on ROS effects using the endothelium of rabbit abdominal aorta to examine if their anti-oxidizing effects can suppress or reduce the vascular endothelium injury by ROS. In this study, both MPD and CRT dose-dependently protected endothelial-dependent relaxation by removing or anti-oxidizing ROS. In addition, their antioxidant effect was not disturbed by pretreatment of 3AT and DETCA.

We generated ROS by direct-electrolysis of a physiologic salt solution, the K-H solution $[19,20]$. It is known that ROS, such as $\mathrm{O}_{2} \cdot \mathrm{H}_{2} \mathrm{O}_{2}, \mathrm{OH} \cdot$, are generated during the physiologic salt solution electrolysis [21-24]. We did not add normal levels of ascorbic acid $\left(1.1 \times 10^{-4} \mathrm{M}\right)$ into $\mathrm{K}-\mathrm{H}$ solution to exclude its antioxidizing effect. In one study, using mouse chest aorta, it was reported that 5 minutes of electrolysis was required to induce injury by ROS [19]. However, 5 minutes of electrolysis with $15 \mathrm{~mA}$ constant current caused too much injury by ROS in the rabbit abdominal aorta, and the ROS generated by 35 seconds of electrolysis was sufficient for this study.

It was reported that vascular relaxation induced by ACh is caused by induced-release of $\mathrm{NO}$ in the vascular endothelium, and that ROS inactivates NO [25-27]. In addition, the ROS

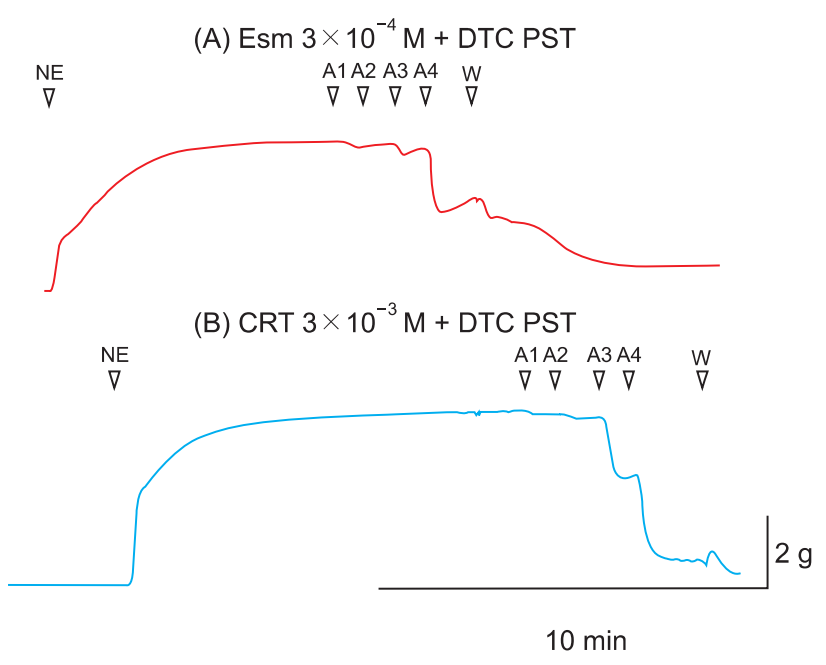

Fig. 5. The relaxation of esmolol $3 \times 10^{-4} \mathrm{M}$ pretreated group was disturbed by DETCA $0.5 \mathrm{mM}(\mathrm{A})$, but the relaxation of hydrocortisone $3 \times 10^{-3} \mathrm{M}$ pretreated group was not affected by DETCA $0.5 \mathrm{mM}$ (B). NE: norepinephrine, A 1-4: acetylcholine $3 \times 10^{-8}, 10^{-7}, 3 \times 10^{-7}$ and $10^{-6} \mathrm{M}, \mathrm{W}$ : K-H solution washing, Esm: esmolol, CRT: hydrocortisone, DTC = DETCA: diethylthiocarbamate, PST: after ROS exposure.

generated by ischemia or reperfusion causes the vascular endothelium injury $[22,28]$. In this experiment, after ROS was generated by 35 seconds of electrolysis, the K-H solution was replaced by a new solution, and the measurement was carried out following 15 minutes of the equilibrium period. As the measurement was carried out following the removal of ROS in this manner, blocking of the ACh vascular relaxation induction effect is assumed to be the result of the direct vascular endothelium injury by ROS, not the result of NO inactivation by ROS [26].

In this experiment, the optimal concentration of 3AT ( $5 \mathrm{mM})$ 
as catalase inhibitor was known from the previous study [11], but the optimal concentration of DETCA was not known. Before the main study, an earlier additional study was carried out to find the optimal concentration of DETCA that attenuates the superoxide scavenging effect. $\beta$-Blockers are strong antioxidants with the effects of scavenging lipid peroxyl radicals, and their antioxidant effects such as ROS scavenging are attenuated by DETCA $[29,30]$. In these experiments, among $\beta$-blockers, esmolol was used as an agent to find the optimal concentration of DETCA. Incremental doses of DETCA were pretreated (0.1, $0.2,0.3$, and $0.5 \mathrm{mM}$ ), and DETCA $0.5 \mathrm{mM}$ interrupted the antioxidant effects of esmolol. Unlike the CRT group, significant attenuation of Ach-induced relaxation was found in the DETCA $0.5 \mathrm{mM}$ pretreated esmolol group compared with the unpretreated group (Fig. 5).

In the study of the vascular relaxation after vascular endothelial injury induction with ROS, the MPD and CRT groups were relaxed by $\mathrm{ACh}$ in a dose-dependent manner. In MPD and CRT $3 \times 10^{-3} \mathrm{M}$ groups, with relatively high concentrations compared with MPD and CRP $10^{-4}$ and $3 \times 10^{-4}$ groups, enhanced ACh-induced relaxation was observed. These findings suggest that MPD and CRT preserve the endotheliumdependent vasorelaxation against the attack of ROS, in a doserelated manner.

$\mathrm{O}_{2} \cdot$ is the first ROS which may lead to secondary radicals such as $\mathrm{H}_{2} \mathrm{O}_{2}$ and $\mathrm{OH} \cdot \mathrm{O}_{2} \cdot$ is converted by superoxide dismutase to $\mathrm{H}_{2} \mathrm{O}_{2}$, which eventually becomes $\mathrm{H}_{2} \mathrm{O}$ by catalase. However, excess $\mathrm{O}_{2}$ is converted by the Fenton reaction and Haber-Weiss reaction to $\mathrm{OH} \cdot$, which is another pathway of ROS. In the study of the effects of 3AT and DETCA on vascular endothelial injury by ROS, the relaxation of the MPD and CRT $3 \times 10^{-3} \mathrm{M}$ groups were not disturbed by pretreatment of 3AT and DETCA. As such, the antioxidant effects of MPD and CRT are not attenuated by pretreatment of 3AT and DETCA and protect the endothelium of abdominal aorta. Endothelial protection mechanisms of MPD and CRT may not be $\mathrm{H}_{2} \mathrm{O}_{2}$ and $\mathrm{O}_{2} \cdot$ scavenging, but the scavenging of $\mathrm{OH}$; , a remainder of ROS. However, to date, there is no specific inhibitor of $\mathrm{OH} \cdot$. Therefore, it is difficult to prove the mechanism of antioxidant effects of MPD and CRT with the manner of specific inhibitors such as 3AT and DETCA. This mechanism may be clarified through further studies with quantitative methods.

With the objective of this study to assess the influences of corticosteroids on the endothelium of rabbit abdominal aorta in ischemia and reperfusion, there are a few limitations. First, the clinically relevant concentration and relative potency of MPD and CRT could not be considered. The major difference between the two is that MPD has a $5: 1$ potency of glucocorticoid and $<0.01: 1$ potency of mineralocorticoid compared to CRT. However, it was shown that there were dose-dependent protective effects of endothelium in two group. Therefore, it is believed that both MPD and CRT have antioxidant effects in ischemia and reperfusion. Second, clinical implication must be tempered by the fact that these results were obtained in a conduit-vessel-like aorta, because the diameter of true resistance vessels to regulate organ blood flow is $100-300$ $\mu \mathrm{m}$. Despite this, it was shown that corticosteroids preserved endothelium-dependent vasorelaxation against ROS.

In conclusion, it was tested whether ROS causes dysfunction in the rabbit aorta endothelium after MPD and CRT pretreatment. Pretreatment with MPD and CRT dose-dependently showed anti-oxidizing or ROS removing effects to protect endothelialdependent relaxation in the abdominal aorta after ROS exposure. DETCA (superoxide dismutase inhibitor) and 3AT (catalase inhibitor) did not attenuate its protective effect. Further experiment to quantify the ROS is needed to investigate the protective mechanism of steroids.

\section{References}

1. Furchgott RF, Zawadzki JV. The obligatory role of endothelial cells in the relaxation of arterial smooth muscle by acetylcholine. Nature 1980; 288: 373-6.

2. Palmer RM, Ferrige AG, Moncada S. Nitric oxide release accounts for the biological activity of endothelium-derived relaxing factor. Nature 1987; 327: 524-6.

3. Bulkley GB. Free radical-mediated reperfusion injury: a selective review. Br J Cancer Suppl 1987; 8: 66-73.

4. Shatos MA, Doherty JM, Hoak JC. Alterations in human vascular endothelial cell function by oxygen free radicals. Platelet adherence and prostacyclin release. Arterioscler Thromb 1991; 11: 594-601.

5. Lefer AM, Tsao PS, Lefer DJ, Ma XL. Role of endothelial dysfunction in the pathogenesis of reperfusion injury after myocardial ischemia. FASEB J 1991; 5: 2029-34.

6. Prasad K, Kalra J, Bharadwaj L. Cardiac depressant effects of oxygen free radicals. Angiology 1993; 44: 257-70.

7. Musacchio E, Rizzoli V, Bianchi M, Bindoli A, Galzigna L. Antioxidant action of propofol on liver microsomes, mitochondria and brain synaptosomes in the rat. Pharmacol Toxicol 1991; 69: 75-7.

8. de Klaver MJ, Weingart GS, Obrig TG, Rich GF. Local anestheticinduced protection against lipopolysaccharide-induced injury in endothelial cells: the role of mitochondrial adenosine triphosphatesensitive potassium channels. Anesth Analg 2006; 102: 1108-13.

9. Bracken MB, Shepard MJ, Collins WF, Holford TR, Young W, Baskin DS, et al. A randomized, controlled trial of methylprednisolone or naloxone in the treatment of acute spinal-cord injury. Results of the Second National Acute Spinal Cord Injury Study. N Engl J Med 1990; 322: 1405-11.

10. Fischer S, Renz D, Schaper W, Karliczek GF. In vitro effects of dexamethasone on hypoxia-induced hyperpermeability and expression of vascular endothelial growth factor. Eur J Pharmacol 2001; 411: 231-43.

11. Lee SY, Suh JK, Choi JH, Jeon WJ, Cheong MA. Effect of ketorolac and diclofenac on the impairment of endothelium-dependent 
relaxation induced by reactive oxygen species in rabbit abdominal aorta. Korean J Anesthesiol 2010; 59: 196-202.

12. Wilson JX, Gelb AW. Free radicals, antioxidants, and neurologic injury: possible relationship to cerebral protection by anesthetics. J Neurosurg Anesthesiol 2002; 14: 66-79.

13. Hess ML, Manson NH. Molecular oxygen: friend and foe. The role of the oxygen free radical system in the calcium paradox, the oxygen paradox and ischemia/reperfusion injury. J Mol Cell Cardiol 1984; 16: 969-85.

14. Lalu MM, Wang W, Schulz R. Peroxynitrite in myocardial ischemiareperfusion injury. Heart Fail Rev 2002; 7: 359-69.

15. Kato R, Foex P. Myocardial protection by anesthetic agents against ischemia-reperfusion injury: an update for anesthesiologists. Can J Anaesth 2002; 49: 777-91.

16. Hwang YS, Shin CY, Huh Y, Ryu JH. Hwangryun-Hae-Dok-tang (Huanglian-Jie-Du-Tang) extract and its constituents reduce ischemia-reperfusion brain injury and neutrophil infiltration in rats. Life Sci 2002; 71: 2105-17.

17. Kapinya KJ, Prass K, Dirnagl U. Isoflurane induced prolonged protection against cerebral ischemia in mice: a redox sensitive mechanism? Neuroreport 2002; 13: 1431-5.

18. Brodsky SV, Yamamoto T, Tada T, Kim B, Chen J, Kajiya F, et al. Endothelial dysfunction in ischemic acute renal failure: rescue by transplanted endothelial cells. Am J Physiol Renal Physiol 2002; 282: F1140-9.

19. Gumusel B, Tel BC, Demirdamar R, Sahin-Erdemli I. Reactive oxygen species-induced impairment of endothelium-dependent relaxation in rat aortic rings: protection by L-arginine. Eur J Pharmacol 1996; 306: 107-12.

20. Ebel D, Preckel B, You A, Mullenheim J, Schlack W, Thamer V. Cardioprotection by sevoflurane against reperfusion injury after cardioplegic arrest in the rat is independent of three types of cardioplegia. Br J Anaesth 2002; 88: 828-35.

21. Kil HK, Kim WO, Kim SH, Nam YT. Effects of isoflurane and propofol on hydrogen peroxide-induced injury of trachea in guineapig. Korean J Anesthesiol 1999; 37: 303-10.

22. Lamb FS, King CM, Harrell K, Burkel W, Webb RC. Free radicalmediated endothelial damage in blood vessels after electrical stimulation. Am J Physiol 1987; 252: H1041-6.

23. Lamb FS, Webb RC. Vascular effects of free radicals generated by electrical stimulation. Am J Physiol 1984; 247: H709-14.

24. Jackson CV, Mickelson JK, Stringer K, Rao PS, Lucchesi BR. Electrolysis-induced myocardial dysfunction. A novel method for the study of free radical mediated tissue injury. J Pharmacol Methods 1986; 15: 305-20.

25. Jackson CV, Mickelson JK, Pope TK, Rao PS, Lucchesi BR. O2 free radical-mediated myocardial and vascular dysfunction. Am J Physiol 1986; 251: H1225-31.

26. Gryglewski RJ, Palmer RM, Moncada S. Superoxide anion is involved in the breakdown of endothelium-derived vascular relaxing factor. Nature 1986; 320: 454-6.

27. Rubanyi GM, Vanhoutte PM. Superoxide anions and hyperoxia inactivate endothelium-derived relaxing factor. Am J Physiol 1986; 250: H822-7.

28. Chen X, Gillis CN. Effect of free radicals on pulmonary vascular response to acetylcholine. J Appl Physiol 1991; 71: 821-5.

29. Khaper N, Rigatto C, Seneviratne C, Li T, Singal PK. Chronic treatment with propranolol induces antioxidant changes and protects against ischemia-reperfusion injury. J Mol Cell Cardiol 1997; 29: 3335-44.

30. Mak IT, Weglicki WB. Protection by beta-blocking agents against free radical-mediated sarcolemmal lipid peroxidation. Circ Res 1988; 63: 262-6. 